\title{
THE EFFECTS OF EMOTIONAL LABOR ON SOFTWARE QUALITY: THE MODERATING ROLE OF PROJECT COMPLEXITY
}

\author{
*Ayse GUNSEL \\ Kocaeli University
}

\begin{abstract}
Even though previous research has examined the consequences of emotional labor in general in software development projects in particular; there still remains a gap in respect to the influences of emotional labor on software quality. Accordingly, in this paper we examine the relationships among emotional intelligence labor and software quality in terms of operational effectiveness, flexibility and responsiveness, using survey data from 62 software development projects. Moreover, this study explores the moderating effect of project complexity between the EL and the quality of the new software product. The results reveal a positive relationship between the variety of emotions displayed during the projects, operational effectiveness and flexibility while emotional dissonance is found to be negatively associated with flexibility and responsiveness. These findings also indicate that expressing a large range of emotions and feelings in daily team interactions enables teams to launch superior software products when unexpected events make a project complicated and challenging to perform.
\end{abstract}

Keywords: Emotion; Emotional labor; Software Development; Emotional dissonance.

\section{INTRODUCTION}

In western societies, there has always been a tendency to disregard emotions as they are deemed irrational and dysfunctional (Arvey et al. 1998; Ashforth and Humphrey, 1995; Muchinsky, 2000). Particularly western societies supported the concept that the ideal 'professional' is primarily rational and controls emotions. Emotions were thought to be inappropriate in organizations (Mumby and Putnam, 1992) as they are rather assumed to be the "expressive arenas of life, as opposed to the instrumental goal orientation of the business world" (Tran, 1998). However, today`s globalized and dynamic business environments, challenge organizations by increased competition and technological developments, exponential innovations and the acceleration of various discontinuous change processes, which in turn affect feelings and relate to emotional issues. Thus, researchers are beginning to consider emotions and emotional processes as an integral element of organizational life, rather than conceiving the workplace as merely a cold, rational machine (Fineman, 2000; Giardini and Frese, 2004; Schreyögg and Sydow, 2001; Küpers and Weibler, 2008).

As a result, studying the role of emotions and emotional dynamics, such as emotional labor, emotional intelligence or emotional capability, becomes the key to understand organizations in the context of the 'real world' - with all the associated constraints, pressing needs and conflicts - . Since the seminal study of Hochschild (1983), the concept of "emotional labor" is given a great deal of attention in the organizational behavior (OB) theory literature (Domagalski, 1999; Fineman, 2000, Akgun et al., 2009). Emotional labor refers to the effort required to create and maintain a desired emotional demeanor (Hochschild, 1983); a core component of which is the regulation of emotions (James, 1989).

Emotional labor is considered of particular importance to new product development teams in general, software development teams in particular based on the fact that the key to improve software development process' productivity and software quality is to focus on human aspects instead of technical ones (Graziotin et al., 2014). Social interactions during the software development projects elicit many emotions (Reus and Liu, 2004). Thus a team's capacity to instill or control the emotions of people through organizational processes to achieve a desired end or to perform a particular task or value activity represent valuable 'resources' for team success (Akgün, et al.2010; Gunsel and Acikgoz 2013). In this vein emotions and emotional issues has started to receive attention in software development era. For instance Rutner et al. (2008), examined emotional dissonance of IT professionals and found that the dissonance has a strongest and consistent relationship with work exhaustion and job satisfaction. Akgün et al (2010) investigated the role of 
emotional capability within software development teams and provided empirical evidence in support of the relationship between emotional capability of software development teams and project outputs. Günsel and Acıkgöz (2013) provided new insight about the role of team flexibility and emotional intelligence on software project on new product development speed, market success and software functionality. Graziotin et al. (2014), emphasized the link between the affective states of the software developers and their ultimate performance.

While the role of emotions in causing, moderating or mediating events and interactions in software development projects (e.g., Rutner et al. 2008; Akgun et al.,2010; Gunsel and Ackkgöz 2013; Graziotin et al., 2014) have received a considerable attention in previous research, the empirical examinations of how emotions and emotional labor impact team interaction and effectiveness are scarce. Our present study aims to fill the research gap by theoretically and empirically examining the consequences of emotional labor within the context of software development teams. Also project complexity on the relationship between emotional labor and software quality should be investigated due to the dominant assumption that complexity makse the software development project more complicated and challenging to perform Geraldi (2009). Specifically, we examine two key issues: (i) What is the relationship between emotional labor and the quality of new software product?, (ii) to what extent are the effects of emotional labor on software quality moderated by project complexity?

The remainder of the paper is organized as follows. Section 2 provides a review of the related literature, thus establishing a clear theoretical ground and describes the hypotheses of the research, whilst section 3 presents the empirical results which test the validity of our hypotheses. In the section 4 the discussion of the findings is provided

\section{LITERATURE REVIEW AND HYPOTHESES}

The following literature review is intended to provide a theoretical base for the role and importance of emotional labor for software development projects. As a challenging problem solving and decision making process, software development includes considerations related to customer requirements, time, competition, quality issues, and a vision of the future (Açıkgoz et al., 2014). Faced with the complexity of software process (including discovery, development, testing and launch) organizations recognize the power of a project-based approach and implement project management applications (Hillson, 2004). Software development, as a specific product development area, is inherently a group process, which requires the concerted efforts of all team members (Qiu, et al., 2009). Even the software development projects involve both cognitive and technical dimensions; the success of such projects in terms of time, cost and quality, also seems to be closely related to emotional issues. Thus the review begins with an overview of the concept of emotional labor; furthermore the dimensions of emotional labor are discussed. This is followed by a hypothesis development part, providing more details and discussions about the link between emotional labor and software quality within the context of software development projects.

\section{Emotional Labor}

Since the seminal study of Hochschild (1983) on the "emotional labor" and Fineman (1993) on the "emotions in organizations. the term "emotion," has attached a great deal of attention in the OB theory (Domagalski, 1999; Fineman, 1993; Akgun et al., 2009). Emotions are related with those "feelings" (Akgün et al., 2009) that comprise an immediate, automatic, and sometimes uncontrollable effect on human behavior and performance (Ostell, 1996). Emotions are also conceptualized as an organized response system that transforms physiological, perceptual, experiential, and cognitive changes into sound experiences of moods and feelings (Mayer et al., 2000). No doubt emotions are common to all human beings in any time and place including the work; from moment of frustration or joy, grief of fear, to an enduring sense of dissatisfaction or commitment, the experience of work is saturated with feelings (Petrides and Furnham, 2003) In this vein, students of $\mathrm{OB}$ theory emphasize that emotions are part of the organizational life and they permeate the workplace, as the organizations are composed of the people, and people have emotions (see, Ashforth and Humphrey, 1995; Domagalski, 1999). 
The term "emotional labor. as the sum of efforts required to create and maintain a desired emotional demeanor, is first coined by Hochschild $(1979,1983)$. Hochschild claims that service agents carry out emotional labor when they express socially desired emotions as part of their job role. The most familiar example to emotional labor is "service with a smile" throughout which waiters and other service workers act welcoming and friendly toward customers and clients (Pugh, 2001). There are three main conceptualizations of emotional labor in OB literature, Each of them assume that emotions are being managed at work in order to meet the display rules stated by the organization and address the individual or organizational outcomes of emotional labor (Grandey, 2000). First, Hochschild (1983) claims the term emotional labor refer to "the management of feeling to create a publicly observable facial and bodily display" (p. 7). Hochschild's work takes its roots from the dramaturgical perspective of customer interactions.

Following Hochschild, Ashforth and Humphrey (1993) put forward a definition of emotional labor as the act of displaying appropriate emotions, with the goal to engage in a form of impression management for the organization. While Hochschild states that "organizations developed feeling rules that specified the emotions that employees should feel; Ashforth and Humphrey (1993) insists on calling these organizational rules as "display rules" due to their link to observable behaviors (emotional expressions) rather than to unseen internal feelings. Ashforth and Humphrey (1993) and other scholars who used the term "display rules" recognize that, employees need to shape their internal emotional status appropriately to display appropriate emotions. In a sense, in contrast with Hochschild's (1983) perspective, this new definition was more concerned with emotional labor as an observable behavior than as a management of feelings, emphasizing the relationship between these observable expressions and task effectiveness or performance (Grandey, 2000).

Finally Morris and Feldman (1996), based on an interactionist approach, conceptualize emotional labor as "the effort, planning, and control needed to express organizationally desired emotion during interpersonal transactions" (p. 987). These authors consider emotional labor to be composed of four main dimensions: (a) frequency of interactions, (b) attentiveness (intensity of emotions, duration of interaction), (c) variety of emotions required, and (d) emotional dissonance. Emotional dissonance was formerly underlined by Hochschild (1983) as a state wherein the emotions expressed are discrepant from the emotions felt. Surface and deep acting, addressed both by Hochschild (1983) and Ashforth and Humphrey (1993), are regarded as a sub component within the dimension of attentiveness. Emotional dissonance, which refers to a the conflict between norms of emotional display and an employee's felt emotion is considered to have negative outcomes such as job dissatisfaction and emotional exhaustion.

\section{Software Quality}

The term "quality" refers to degree of how well any product satisfies its customers' requirements (Nidumolu 1995). The ISO/IEC 9126-1 standards (2001) underlines the key quality factors for software products: functionality (the capability to provide functions which meet stated and implied needs), reliability (the capability to maintain its level of performance under stated conditions), usability (the capability to be understood, learned, and used by users), efficiency (the capability to provide appropriate performance relative to the amount of resources used), maintainability (the capability to be modified through corrections, improvements, and adaptations), and portability (the capability to be transferred from one platform to another). In parallel to this, Açikgoz et al (2014) recategorised software quality into three factors as follows: (i) operational efficiency (functionality and efficiency), (ii) flexibility (maintainability and portability), and (iii) responsiveness (reliability and usability).

The software development process is related to customer requirements, time pressure, and quality issues. In this direction, it is crucial to understand what is necessary to produce high quality software products successfully -within a given time frame and budget- in order to meet customer requirements (Akgün et al. 2010; Günsel and Açıgöz 2013). Human aspects - individual team members and their interactions over processes and tools - play an important role in the execution of software development process and the quality of resulting products (Colomo-Palacios et al., 2010; Graziotin et al., 2014). Software development as a knowledge intensive work group activity is closely dependent upon how team members work together toward a common goal (Qiu and Peschek, 2012). Thus, the quality of the new software product cannot be viewed as the outcome of mere individual attempts; it requires collective actions and intensive teamwork to be successfully completed (Lin et al., 2011). Any single team member who works in isolation will be at a 
disadvantage compared to a team of individuals who can utilize the entirety of the team members' contributions (Qiu and Peschek, 2012). Especially, the literature indicates that the success of software projects depends on the interaction of knowledge and skills, which essentially a process that requires cross functional integration and intense social interactions among team members (Nicholson and Sahay, 2004; Hoegl and Parboteeah, 2007). In other words the members and the interactions among them on the project are good enough, they can use almost any process and accomplish their assignment and produce new software products of quality; otherwise no process will repair their inadequacy (Highsmith and Cockburn, 2001). Thus it is crucial to examine the human aspects that lies beneath the positive environment and effective social relationships that are necessary to produce high quality software products successfully (Akgün et al. 2010; Günsel and Açkgözz 2013).

Without any doubt, hostess and sales clerks are expected to be cheerful, police officers are expected to be authoritative, while the nurses to be compassionate. Even though no one has studied display rules and emotional labor in software development context yet as to our knowledge, one can infer emotional display expectations from the very nature of the software development projects. For example, as team members, software developers need to show concern for their team mates within a cross functionally composed team, rather than just technical, functions. Technically focused members who convey an attitude of indifference toward software product members from different backgrounds with differing talents such as artists, designers (Markus and Benjamin 1996). While systems development often involves conflict (Barki and Hartwick 2001), software developers may feel they should not display anger when conflict arises. IT professionals and project leaders may be expected to display neutrality when making work assignments or sternness when dealing with underperforming subordinates. These examples illustrate just a few possible software display rule expectations (Rutner et al., 2008). Accordingly we expect the members of software development teams to perform emotional labor to produce high quality software products successfully - within a given time frame and budget - in order to meet customer requirements. Particularly when the members more frequently interact with each other (e.g. frequency of interactions), discuss their ideas and different perspectives to come to a common ground, in a positive manner, (b) attentiveness (intensity of emotions, duration of interaction), (c) show their feeling without a fear of reprisal (e.g. variety of emotions); they easily communicate and collaborate. As a result, software development teams, composed of members that perform emotional labor, can easily go beyond the uncertainties about customer expectations, business needs, and environmental changes. In this vein, we argue that a) frequency of interaction, b) attentiveness, c) variety of emotions within in a software development team can positively contribute to developing superior software products in ord er to meet stated and implied needs, adapt to instable business and environmental needs, and generate userfriendly products. Accordingly;

H1: Emotional labor: frequency of interaction, is positively related to software quality in terms of 1a) operational efficiency, $1 \mathrm{~b}$ ) flexibility, and 1c) responsiveness.

H2: Emotional labor: attentiveness is positively related to software quality in terms of 2 a) operational efficiency, 2b) flexibility, and 2c) responsiveness.

H3: Emotional labor: variety of emotions is positively related to software quality in terms of 3 a) operational efficiency, 3b) flexibility, and 3c) responsiveness.

However, emotional dissonance - the conflict between norms of emotional display and members felt emotion- seems to differ than the other dimensions of the emotional labor. No doubt software development is a complicated process that involves convergence of the ideas and thoughts of different members -technical ones and artistic ones- from different backgrounds and specialization areas in a collaborative manner. Members, may need to suppress the display of anger or irritation due to the professional requirements, may feel lonely and marginalized from the team. Any marginalized - or at least feels to be so- single team member who works in isolation will be at a disadvantage compared to a team of individuals who can utilize the entirety of the team members' contributions (Qiu and Peschek 2012). Thus, the imposition of team related requirements upon personal expressions may create negative reactions in team members which ultimately may harness the cross functional integration and team collaboration. Indeed the previous studies abound of evidence for the negative outcomes of emotional dissonance. For instance Morris and Feldman (1997) discover that emotional dissonance relates positively to work exhaustion and negatively to job 
satisfaction; whereas they find other emotional labor dimensions (e.g., interaction frequency and duration) do not. Likewise, Lewig and Dollard (2003) come to the conclusion emotional dissonance predicts exhaustion and satisfaction. while other dimensions do not. Even Diik and Brown. (2006) claim that conflicting empirical findings in studies assessing the relationship between emotional labor and negative iob outcomes are partly due to the lack of clarity regarding the conceptualization and measurement of emotional dis sonance. Accordingly:

H4: Emotional labor: emotional dissonance is negatively related to software quality in terms of 4a) operational efficiency, 4b) flexibility, and 4c) responsiveness.

\section{Moderator Effect: Project Complexity}

As claimed by the Standish Group (2001), only 16-28\% of information technology projects (e.g., software development projects) can be considered successful (i.e., completed within a given time frame and budget with all features and functions as originally specified). The main reason underlying the low rates of success may be that developing any software product is a highly complex process because of the interaction of a large number of parts in non-traditional ways (Açlkgöz et al., 2014). Here the term "complexity" means something unwanted that makes the software development project more complicated and difficult to perform (Geraldi, 2009). Project complexity often enforces team members to dependently work together; they should develop and implement new solutions collectively and collaboratively. Particularly software development is a complex problem solving and decision making process (Gallivan, 2003; Akgün et al., 2010). Thus complexity seems to be a real challenge for software development projects. In order to overcome this challenge we expect team members to (i) more frequently interact with each other (e.g. frequency of interactions), discuss their ideas and different perspectives to come to a common ground, in a positive manner, (b) show attention to each other (e.g. attentiveness), (c) show their feeling without a fear of reprisal (e.g. variety of emotions). As a result, we use project complexity as a moderator because we believe that the project complexity moderates the relationships between the first three dimensions of emotional labour frequency of interactions, attentiveness, variety of emotions- and software quality. Accordingly, we hypothesize as follows:

Hypothesis 5 Project complexity positively moderates the relationship between frequency of interactions and software quality in terms of 5a) operational efficiency, 5b) flexibility, and 5c) responsiveness.

Hypothesis 6 Project complexity positively moderates the relationship between attentiveness and software quality in terms of 6a) operational efficiency, 6b) flexibility, and 6c) responsiveness .

Hypothesis 7 Project complexity positively moderates the relationship between variety of emotions and software quality in terms of 6a) operational efficiency, 6b) flexibility, and 6c) responsiveness.

However we note that, the complexity may also create negative emotions and attitudes towards team work and project. The experience of emotional conflict between norms of emotional display and members felt emotion (e.g. emotional dissonance) may lead more dysfunctional outcomes -such as low job satisfaction, stress, anxiety, crisis, low organizational commitment, and other outputs particularly when the project is dominated by various amounts of interaction patterns in untraditional form (Fox et al., 2001). Anxiety and crisis emerge to pass as result of those unfamiliar interaction patterns. Thus we expect the association of anxiety and crisis with emotional dissonance, to moderate the relationships between the emotional dissonance and software quality. Accordingly, we hypothesize as follows:

Hypothesis 8 Project complexity negatively moderates the relationship between emotional dissonance and software quality in terms of 6a) operational efficiency, 6b) flexibility, and 6c) responsiveness. 


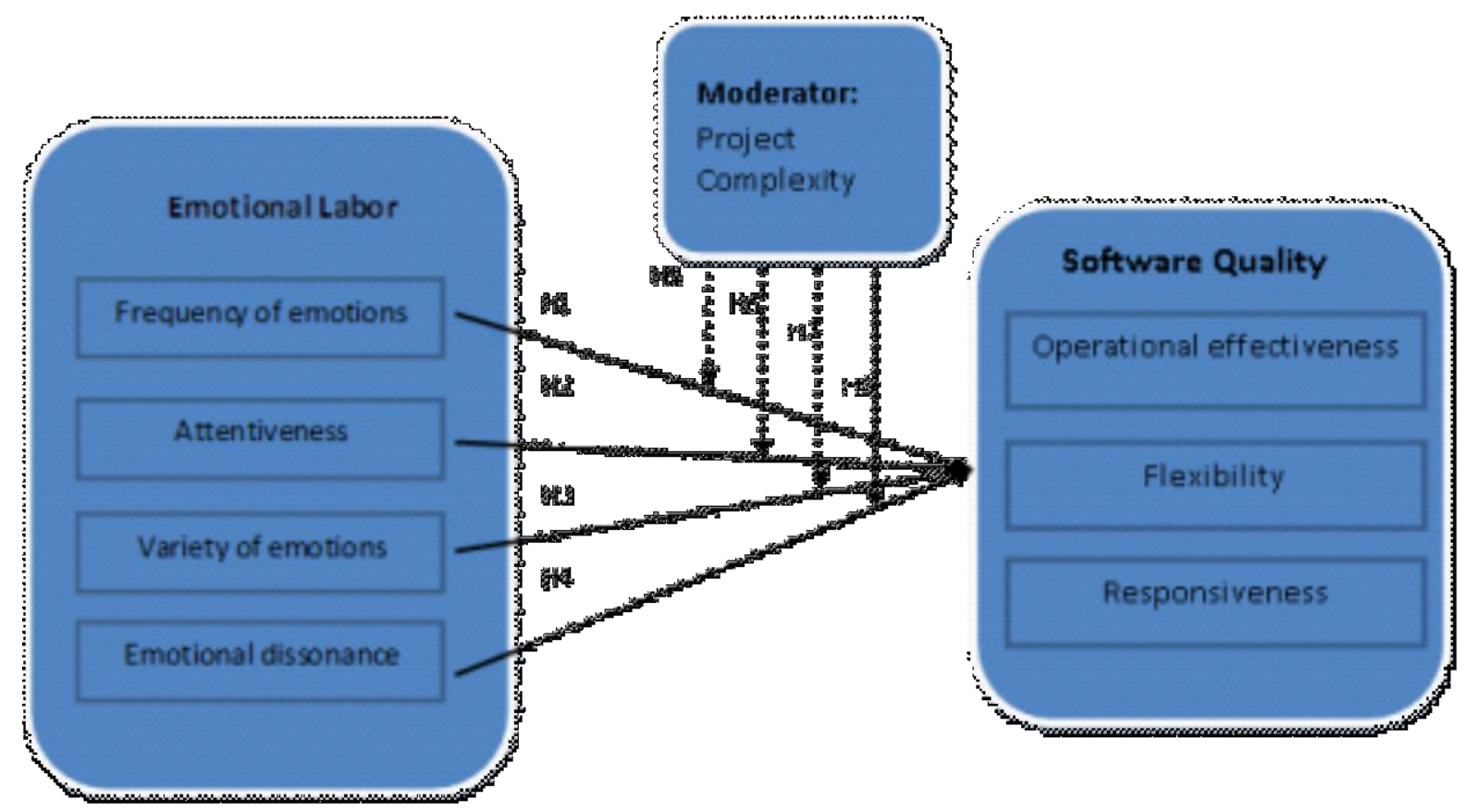

Figure 1: Research Model

\section{METHODOLOGY}

\section{Measures And Sample}

To test the above hypotheses, multi-item scales adopted from prior studies for the measurement of constructs were used. Each construct was measured using 5-point Likert scales ranging from "strongly disagree" (1) to "strongly agree" (5). However, project team size, as a control variable, question was assessed with ratio scale. Appendix demonstrates our measures. A brief summary of the measures follows.

For emotional labor as a four dimensional construct, we adopted for dimensional the emotional labor scale from the studies of Brotheridge, and Lee (2003), Diefendorff et al., (2005) and Cheung and Tang, (2012). Regarding the software quality in terms of operational effectiveness, flexibility and responsiveness, we adopted Açıkgöz et al's (2014) software quality scale who derived these items from Nidumolu (1995).

Project complexity, as a degree to which the development process is complicated and difficult, is closely related to the similarity of the development, commercialization, and communication processes used during the project compared to the previous projects. In this vein, we adopted the three-item complexity scale, developed by Lynn and Akgün (1998).

The initial sample was obtained from 99 firms, which were either directly operating in the software development industry or had a software development department, based on records supplied by the Istanbul Chamber of Commerce. Initially, the managers of these firms were contacted by telephone so that we could explain the aim of our study. Specifically, the respondents were informed that they should be the software engineers/developers who were the most knowledgeable about their software development projects. Of the 99 firms contacted 52 agreed to participate in this study out of which 37 firms completed our questionnaire (for a response rate of $71 \%$ ). A total of 62 questionnaires were returned (several firms participated in our study with more than one respondent but each respondent were asked to evaluate one unique project). In terms of organizational sampling distribution, $78 \%$ of the projects were from information and communication technology organizations, $14 \%$ of them were from business service organizations, and $8 \%$ of the projects were related to financial service organizations. 


\section{Measurement Validation}

We used the partial least squares (PLSsmart 2.0) approach to path modeling to estimate the measurement and structural parameters in our structural equation model (SEM). We evaluated reliability by means of composite scale reliability (CR) and average variance extracted (AVE). For all measures except frequency of interaction dimension of emotional labour, PLS-based CR is well above the cut-off value of .70, and AVE exceeds the .50 cut-off value. In addition, we evaluated convergent validity by inspecting the standardized loadings of the measures on their respective constructs and found that all measures again except frequency of interaction exhibit standardized loadings that exceed .60. In order to understand why this construct frequency of interaction- doesnt t represent statistically significant results; one may look beyond the nature of the software development teams. Unlike new product development, the development of software often involves a variety of team members who work at different times and in different places and have high levels of individual sovereignty. As a result, interactions may not come to pass as we experience in traditional organizations or teams. For instance software developers may be communicating largely through emails and thev access the software product at the time being developed and take over their role or share data in dramatically easier ways through a cloud system. In this vein, we dropped this dimension -fully rejecting H1- and reconfigured the research model (figure 2).

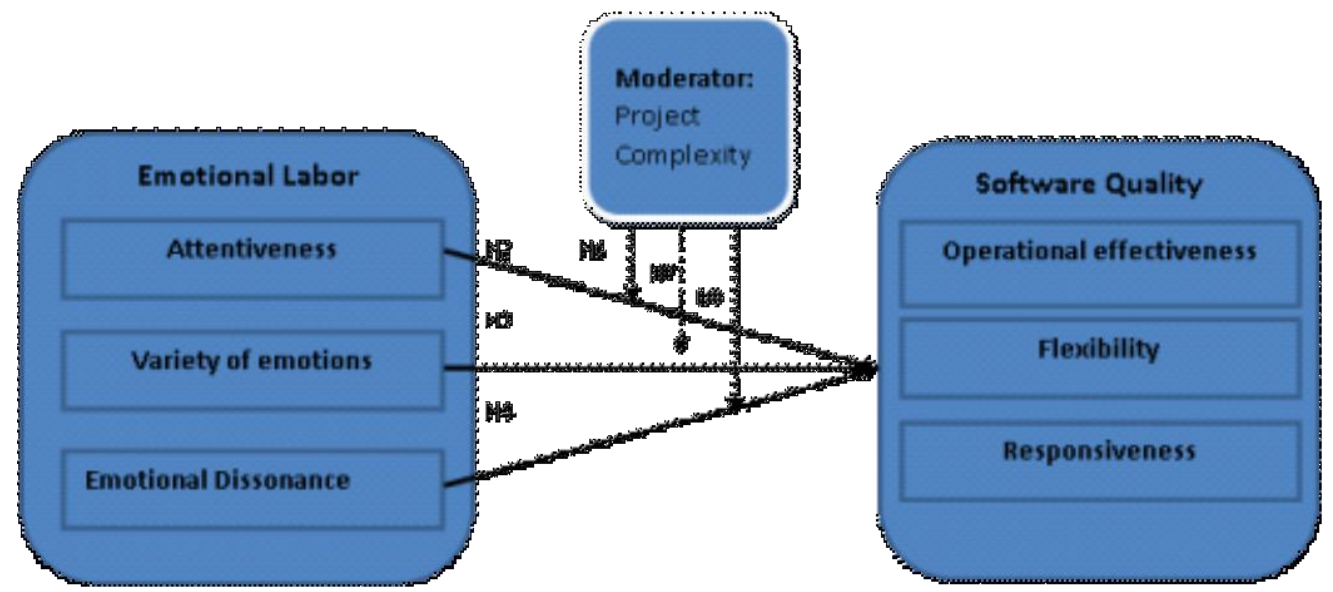

\section{Figure 2: Reconfigured Research Model}

We next assessed the discriminant validity of the measures. As suggested by Fornell and Larcker (1981), the $\mathrm{AVE}$ for each construct was greater than the squared latent factor correlations between pairs of constructs for the new model (see, Table 1).

\section{Table 1: CR, AVE and correlations}

\begin{tabular}{|l|l|l|l|l|l|l|l|l|l|l|}
\hline & C.R. & AVE & $\mathbf{1}$ & $\mathbf{2}$ & $\mathbf{3}$ & $\mathbf{4}$ & $\mathbf{5}$ & $\mathbf{6}$ & $\mathbf{7}$ & $\mathbf{8}$ \\
\hline Frequency & .51 & .49 & -- & & & & & & & \\
\hline Attentiveness & .94 & .72 & .24 & - & & & & & & \\
\hline Variety & .72 & .60 & $.41^{*}$ & $.70^{* *}$ & -- & & & & & \\
\hline Dissonance & .96 & .87 & $-.34^{* *}$ & $-.62^{* *}$ & $-.54^{* *}$ & -- & & & & \\
\hline Project complexity & .96 & .90 & .02 & $.50^{* *}$ & $.60^{* *}$ & $-.52^{* *}$ & -- & & & \\
\hline Op. effectiveness & .97 & .89 & .17 & .28 & $.45^{* *}$ & $-.31^{*}$ & $.58^{* *}$ & -- & & \\
\hline Flexibility & .97 & .89 & .08 & $.55^{* *}$ & $.52^{* *}$ & $-.57^{* *}$ & $.68^{* *}$ & $.65^{* *}$ & -- & \\
\hline Responsiveness & .97 & .89 & $.45^{*}$ & $.54^{* *}$ & $.43^{* *}$ & $-.54^{*}$ & $.64^{*}$ & $.69^{* *}$ & $.65^{* *}$ & -- \\
\hline
\end{tabular}

$$
\text { " } P<.05, \quad P<.01
$$




\section{Hypothesis Testing}

We used PLS path modeling which allows for explicit estimation of latent variable (LV) scores, to estimate the main effects in our model (see Figure 2). We used PLSsmart 2.0and Bootstrapping resampling method to test their statistical significance. This procedure entailed generating 500 sub-samples of cases randomly selected, with replacement, from the original data. Path coefficients were then generated for each randomly selected subsample. T-statistics were calculated for all coefficients, based on their stability across the subsamples, indicating which links were statistically significant.

As shown in Table 2, the results illustrate that our hypotheses -in the revised model- are largely confirmed. We found that variety of emotions is positively associated with operational efficiency and $(\beta=., p<.01)$ and flexibility $(\beta=. \mathrm{xx}, \mathrm{p}<.01$, largely supporting H3. Next, our results demonstrated that - as we expectedemotional dissonance is negatively associated with flexibility $(\beta=., p<.01)$ and responsiveness $(\beta=., p<$ .1), largely supporting H4. Further, interestingly we could not found any statistical association between attentiveness and any dimensions of software quality, not supporting $\mathrm{H} 2$.

Finally, the model presented in figure 2 -three dimensional emotional labor construct- explain $22 \%$ of variance $\left(R^{2}=.22\right)$ in operational effectiveness, $40 \%$ of flexibility $\left(R^{2}=.40\right)$, and $30 \%$ of responsiveness $\left(R^{2}\right.$ $=.30)$ in quality of new software products.

Table 2: Path analyses (SEM)

\begin{tabular}{|c|c|c|c|c|c|}
\hline Relationships & Path Coefficient ( $\beta$ ) & Sub-hypotheses & Sub-results & Hypotheses & Results \\
\hline $\mathrm{AT} \rightarrow \mathrm{OE}$ & -.18 & $\mathrm{H} 2 \mathrm{a}$ & Not Supported & $\mathrm{H} 2$ & Partially Supported \\
\hline $\mathrm{AT} \rightarrow \mathrm{FL}$ & .12 & $\mathrm{H} 2 \mathrm{~b}$ & Not Supported & & \\
\hline $\mathrm{AT} \rightarrow \mathrm{RE}$ & $.16^{*}$ & $\mathrm{H} 2 \mathrm{c}$ & Supported & & \\
\hline $\mathrm{VE} \rightarrow \mathrm{OE}$ & $.48^{* * * *}$ & $\mathrm{H} 3 \mathrm{a}$ & Supported & H3 & Supported \\
\hline $\mathrm{VE} \rightarrow \mathrm{FL}$ & $.26^{* * * *}$ & $\mathrm{H} 3 \mathrm{~b}$ & Supported & & \\
\hline $\mathrm{VE} \rightarrow \mathrm{RE}$ & $.15^{*}$ & $\mathrm{H} 3 \mathrm{c}$ & Supported & & \\
\hline $\mathrm{ED} \rightarrow \mathrm{OE}$ & -.19 & $\mathrm{H} 4 \mathrm{a}$ & Not Supported & $\mathrm{H} 4$ & Mariginally \\
\hline $\mathrm{ED} \rightarrow \mathrm{FL}$ & $-.35^{* * *}$ & $\mathrm{H} 4 \mathrm{~b}$ & Supported & & Supported \\
\hline $\mathrm{ED} \rightarrow \mathrm{RE}$ & $-.32^{* * *}$ & $\mathrm{H} 4 \mathrm{c}$ & Supported & & \\
\hline $\mathrm{AT} * \mathrm{PC} \rightarrow \mathrm{OE}$ & -.74 & H6a & Not Supported & H6 & Not Supported \\
\hline $\mathrm{AT} * \mathrm{PC} \rightarrow \mathrm{FL}$ & -.68 & H6a & Not Supported & & \\
\hline $\mathrm{AT} * \mathrm{PC} \rightarrow \mathrm{RE}$ & -.29 & H6a & Not Supported & & \\
\hline $\mathrm{VE} * \mathrm{PC} . \rightarrow \mathrm{OE}$ & -.20 & $\mathrm{H} 7 \mathrm{a}$ & Not Supported & $\mathrm{H} 7$ & Partially Supported \\
\hline $\mathrm{VE} * \mathrm{PC} \rightarrow \mathrm{FL}$ & $.52 * * *$ & $\mathrm{H} 7 \mathrm{~b}$ & Supported & & \\
\hline $\mathrm{VE} * \mathrm{PC} \rightarrow \mathrm{RE}$ & $.31 * * *$ & $\mathrm{H} 7 \mathrm{c}$ & Supported & & \\
\hline $\mathrm{ED} * \mathrm{PC} \rightarrow \mathrm{OE}$ & .01 & $\mathrm{H} 8 \mathrm{a}$ & Not Supported & $\mathrm{H} 8$ & Not Supported \\
\hline $\mathrm{ED} * \mathrm{PC} \rightarrow \mathrm{FL}$ & -.34 & $\mathrm{H} 8 \mathrm{~b}$ & Not Supported & & \\
\hline $\mathrm{ED} * \mathrm{PC} \rightarrow \mathrm{RE}$ & -.73 & $\mathrm{H} 8 \mathrm{c}$ & Not Supported & & \\
\hline $\begin{array}{l}\text { Indigenous } \\
\text { Construct }\end{array}$ & $\overline{\mathbf{R}^{2}}$ & & & & \\
\hline $\mathrm{OE}$ & .22 & & & & \\
\hline FL & .40 & & & & \\
\hline $\mathrm{RE}$ & .30 & & & & \\
\hline
\end{tabular}

AT: Attentiveness, OE: Operational Efficiency, FL: Flexibility, RE: Responsiveness, VE: Variety of Emotions, ED: Emotional Dissonance 


\section{CONCLUSION}

In this study, we tried to offer a contribution to project management literature by presenting a model for researchers and managers and project leaders to understand potential interrelationships among emotional labor and the software quality. The results of this paper reveal several findings that have important implications for both research and practice.

First, we started our way through a four dimensional emotional labor construct, composed of frequency of interaction, attentiveness, variety of emotions displayed and emotional dissonance, as Morris and Feldman (1997) suggested. However our findings showed that frequency of interaction scale, which is mainly developed and used for organizational settings were not proper for software development context. This inconsistency may be attributed to the very nature of the software development projects whose members may work in widely different locations, such as America and India, and time zones unlike traditional organizational and team settings, emphasizing a virtual work environment. Thus we reconstructed our model with a three dimensional emotional labor construct composed of attentiveness, variety of emotions displayed and emotional dis sonance.

Second, we empirically demonstrated the role of attentiveness -the first dimension of emotional labor- on software quality. Interestingly the findings showed no significant association between attentiveness and any facet of software quality. Attentiveness refers to the intensity and duration of the social interaction among the members. As pointed out before, software development projects highlights a specific type of team work involving members with high levels of autonomy, working at different time zones and in different places. The intensity and extent of mutual emotional interactions may not be so significant for this very nature of software development projects. Another explanation for this unsupported relationship is that attentiveness may be more likely to influence the quality of new software product via other emotional labor dynamics due to the high correlation between them. For instance one dynamic may be triggering the other.

Third, we examined the effects of the variety of the emotions on software quality. The findings revealed strong relationships between the variety of emotions displayed within a software project and the operational efficiency and flexibility. This suggests that when the team members perform greater effort to exhibit and orient their surface and deeper feelings to create and maintain a desired goal without the fear of reprisal; in this more collaborative and interactive team environment they can produce new software products that meets or extends the expectations towards functionality, efficiency, maintainability and portability.

Fourth, we searched for the consequences of emotional dissonance - the final dimension of emotional laboron software quality. The findings showed that emotional dissonance was negatively associated with the flexibility and responsiveness within software development projects. When the members embrace a conflict between the team norms of emotional display, emotional expectations and their real feelings and emotions, they turn in upon themselves. Dissocialized members are less likely to collaborate and make contribution to team goals. So such software development teams will be at a disadvantage compared to a team of members who can utilize the entirety of the team members' contributions. Therefore, they may fail to meet the quality expectations towards maintainability, portability, reliability and usability

Finally the results of this study show that there is a greater relationship between variety of emotions, and two dimensions of software quality -flexibility and responsiveness- when complexity make the software development project more complicated and challenging to perform. This result underlines that expressing a large range of emotions and feelings -both surface and deeper- in daily team interactions, without a fear of reprisal, enables team members to dependently work together; they can develop and implement new solutions collectively and collaboratively and become successful in dynamic environments. When sudden and unwanted events make a project more complicated and challenging, the intensity and the variety of emotions expressed in team interactions leads the team to launch software products of superior quality. As a result new software product can easily be adapted to changing busines s and environmental requirements, is easier to use, and can provide customized information to meet the needs of the users.

Surprisingly, we could not find any significant relationship between other dimensions of emotional labor and software quality by employing project complexity as a moderator variable. We again attribute this conflicting 
result to the very nature of software development projects, emphasizing a virtual work environment spreading over time zones unlike traditional organizational and team setting.

Although we found no evidence of significant common method bias, use of multiple informants from the same project could have further triangulated the results and increased the reliability and validity of informant reports. While the use of a small number of software development teams would make it easier to obtain data from multiple respondents, field studies of an immature software industry with a small number of teams make it difficult to collect data from multiple informants. Therefore, we rejected the idea of soliciting multiple informants because of the risk of substantially decreasing response rate.

The generalizability of the sample is another limitation of this study. The study was conducted in a specific national context, Turkey, so readers should be cautious in generalizing the results to different cultural contexts.

Despite these limitations, this study provides important implications from theoretical and practical perspectives. This study indicates that emotional variety displayed during the project has direct and positive influences operational efficiency and flexibility of the new software product. In addition, emotional dissonance is found to be negatively related flexibility and responsiveness facets of the software quality. 


\section{REFERENCES}

Açkgöz, A., Günsel, A., Bayyurt N. \& Kuzey, C., (2014). Team Climate, Team Cognition, Team Intuition, and Software Quality: The Moderating Role of Project Complexity. Group Decision and Negotiation 23(5),1145-1176.

Akgün A. E. Keskin, H., Byrne J. \& Günsel, A, (2010). Antecedents and Results of Emotional Capability in Software Development Teams. Journal of Product Innovation Management, 28(6), 957-973

Akgün, A.E. Keskin, H. \& Byrne J.C. (2009). Organizational emotional capability, product and process innovation, and firm performance: An empirical analysis. Journal of Engineering and Technology Management, 26 (3), 103-130.

Arvey, R.D., Renz, G.L., \& Watson,T.W. (1998). Emotionality and job performance: Implications for personnel selection. Research in Personnel and Human Resources Management, 16, 103-147

Ashforth, B.E. \& Humphrey, R.H. (1993). Emotional labour in service roles: the influence of identity. Academy of Management Review, 181 pp. 88-115.

Ashforth, B.E. \& Humphrey, R.H. (1995). Emotion in the work place: a reappraisal. Human Relations, 48 , 97-125

Ashkanasy, N. M. (2003). Emotions in organizations: A multi-level perspective. Multi-Level Issues in Organizational Behavior and Strategy Research in Multilevel Issues2: 9-54.

Barki, H \& Hartwick J., (2001). Interpersonal conflict and its management in information system development. MIS Quarterly 25(2), 195-208.

Brotheridge, C.M. \& Lee, R.T. (2003). Development and validation of the emotional labour scale. Journal of Occupational and Organizational Psychology, 76, 365-79.

Cheung, F.Y., \& Tang, C.S., (2012). The effect of emotional dis son ance and emotional intelligence on work-family interference. Canadian Journal of Behavioural Science, 44(1), 50-58. http://dx.doi.org/10.1037/a0025798

Colomo-Palacios, R., Tovar-Caro, E., García-Crespo, A. and Gómez-Berbís, J., (2010). Identifying technical competences of it professionals: The case of software engineers. International Journal of Human Capital and Information Technology Professionals 1(1):31-43.

Diefendorff, J. M., Croyle, M. H., \& Gosserand, R. H. (2005). The dimensionality and antecedents of emotional labor strategies. Journal of Vocational Behavior, 66, 339-357.

Domagalski, T. A. (1999). Emotion in organizations: Main currents. Human Relations, 52(6), 833-852.

Fineman, S. (1993) Emotions in Organisations, Sage, London.

Fineman, S. (2000) Emotion in Organizations, 2nd ed., Sage, London.

Fox, S., Spector, P. E., \& Miles, D. (2001). Counterproductive work behavior (CWB) in response to job stressors and organizational justice: Some mediator and moderator tests for autonomy and emotions. Journal of Vocational Behavior, 59, 291-309.

Gallivan, M.J. (2003). The influence of software developers' creative style on their attitudes to and assimilation of a software process innovation. Information \& Management, 40, 443-465,

Geraldi J.G., (2009). What complexity assessments can tell us about projects: Dialogue between conception and perception. Technology Analysis and Strategic Management 21(5), 665-678

Giardini, A. \& Frese, M. (2004) 'Emotionen in organisationen', in Schreyögg, G. And von Werder, A. (Eds.): Handwörterbuch Unternehmensführung und Organisation, Schaeffer-Poeschel, Stuttgart, 205-214.

Grandey A. A., (2000). Emotion Regulation in the Workplace: A New Way to Conceptualize Emotional Labor. Journal of Occupational Health Psychology (5), 95-110 
Graziotin D, Wang X, Abrahamsson P. (2014). Happy software developers solve problems better: psychological measurements in empirical software engineering. Peer J 2:e 289.

Günsel A. \& Açıkgöz A., (2013). The Effects of Team Flexibility and Emotional Intelligence on Software Development Performance. Group Decision and Negotiation, 22, 9-377.

Highsmith, J. \& A. Cockburn, (2001). Agile Software Development: The People Factor. IEEE Computer, Nov.

Hillson, D. (2004). Effective Opportunity Management for Projects: Exploiting Positive Risk. New York, Marcel Dekker Inc.

Hochschild, A. R. (1983). The managed heart: Commercialization of human feeling. Berkeley, CA: University of California Press.

Hochschild. A, R. (1979). Emotion Work, Feeling Rules, and Social Structure. American Journal of Sociology, 85(3), 551-575

Hoegl, M. \& K.P. Parboteeah. Creativity in innovative projects: How teamwork matters. Journal of Engineering and Technology Management, 24(1-2), 148-166, 2007.

ISO/IEC: FCD 9126-1.2. (2001) Information Technology - Software Product Quality. Part 1:Quality Model. Available at: http://www.iso.org/iso/iso_catalogue/catalogue_tc/catalogue_detail.htm?csnumber=22 749 [Retrieved 10 August 2011]

James, N. (1989). Emotional labour: skill and work in the social regulation of feeling. Sociological Review, 37(1),pp.15-24.

Küpers W.\& Weibler J,. (2008). Emotions in organization: an integral perspective. Int. J. Work Organization and Emotion, 2( 3), 145-157

Lewig, K., \& Dollard, M. F. (2003). Can I help you? Emotional diss onance, emotional exhaustion, and job satisfaction among call centre workers. European Journal of Work and Organizational Psychology, 12, 366392.

Lin, K.Y., J.W. Son \& E. Rojas (2011), Safety Director: A 3D Game Environment for Construction Safety Education. Journal of Information Technology in Construction(ITCON), 2011 special issue "Use of Gaming and Virtual World technology in Architecture, Engineering and Construction".

Markus M.L. \& Benjamin RI, (1996). Change agentry-the next IS frontier. MIS Quarterly 20, (4), 385402.

Mayer, J.D., Salovey, P., \& Caruso, D. (2000). Models of emotional intelligence. In Sternberg, R.J. (ed). Handbook of human intelligence. New York: Cambridge University Press.

Morris, J. H., \& Feldman, D. C. (1997). Managing emotions in the workplace. Journal of Managerial Issues, 9(3), 257-275.

Morris, J., \& Feldman, D. (1996). The dimensions, antecedents, and consequences of emotional labour. Academy of Management Review, 21, 986-1010.

Muchinsky, P. (2000). Emotions in the workplace: the neglect of organizational behavior. Journal of Organizational Behavior, 21(7), 801-805.

Mumby, D. \& Putnam, L. (1992). The politics of emotion: A feminist reading of bounded rationality. Academy of Management Review 17: 465-486

Munchinsky, P. M. (2000). Psychology applied to work: An introduction to industrial and organizational psychology (6th ed.). Belmont, CA: Wadsworth

Nicholson B.\& S. Sahay. (2004). Embedded knowledge and offshore software development. Information and Organization, 14(4), 329-365. 
Nidumolu S., (1995). The effect of coordination and uncertainty on software Project performance: Residual performance risk as an intervening variable. Information Systems Research 6(3), 191-219

Ostell, A. (1996) Managing dysfunctionalemotions in organisations. Journal of Management Studies. 33, 525-557.

Petrides, K. V. , \& Furnham, A. (2003). Trait emotional intelligence: Behavioural validation in two studies of emotion recognition and reactivity to mood induction . European Journal of Personality, 17, $39-57$.

Pugh, S. D., (2001). Service with a smile: Emotional contagion in the service encounter. Academy of Management Journal, 44: 1018-1027.

Qiu T., \& Peschek B. S., (2012). The Effect of Interpersonal Counterproductive Workplace Behaviors on the Performance of New Product Development Teams. American Journal of Management 12(1), 21-33

Qiu, T., Qualls, W., Bohlmann, J. \& Rupp, D. E. (2009). The Effect of Interactional Fairness on the Performance of Cross-Functional Product Development Teams: A Multilevel Mediated Model. Journal of Product Innovation Management 26 (2), 173-187.

Reus T.H. \& Y. Liu, (2005). Rhyme and reason: emotional capability and the performance of knowledgeintensive work groups. Human Performance, 17, 245-266,

Rutner, P., Hardgrave, B., \& McKnight, D. (2008). motional dissonance and the information technology professional. IS Quarterly 32(3), 635-652.

Schreyögg, G. \& Sydow, J. (Hrsg.) (2001) Managementforschung 11: Emotionen und Management, Wiesbaden.

The Standish Group, (2001), The Chaos Report

Tran, V., (1998). The role of the emotional climate in learning organisations.

Learning Organization. 5( 2), 99 - 103.

Van Dijk, P.A. \& Kirk-Brown, A. (2006). Emotional labor and negative job outcomes: an evaluation of the mediating role of emotional dissonance. Journal of Management \& Organization, 12, 101-15. 


\section{APPENDIX-MEASURES}

Standardized loadings are in parantheses.

* denotes the dropped item, either they reduce the AVE less then .50, or they have low loading wieghts.

Project Complexity (developed from Lynn and Akgün,1998)

The development process used in this project was different to the process the team traditionally uses. (.93)

The commercialization process used in this project was different to the process the team traditionally uses. (.96)

The processes used on this project to communicate across functional disciplines, with suppliers and customers were different to the communication process the team traditionally uses. (.95)

Software Quality (developed from Açıgöz et al., 2013)

Operational Effectiveness

The software is reliable (.92)

There is a quick response time by the product (.95)

The client is satisfied with the overall operational efficiency of the software. (.95)

The cost of software operations is efficient. (.95)

Flexibility

The software adapts to changes in business with cost efficiency. (.95)

The software adapts to changes in business requirements. (.96)

The final product achieves overall long-term flexibility of the software. (.93)

\section{Responsiveness}

The software is easy to use (.94)

The software customizes outputs to various client needs .93

The software is responsive overall to client needs. .95

\section{Emotional Labour}

Frequency of Interaction (developed from Diefendorff et al., 2005)

I interact with many different team mates on a daily basis. *

I do encounter a large number of interactions with team mates during my typical work day. *

Attentiveness to Required Display Rules (developed from Diefendorff et al., 2005)

I spend a lot of time with each team mate I interact with. (.86)

Most of my interactions with team mates are long (.76)

I try to actually experience the emotions that I must show to customers . (.87) 
I make an effort to actually feel the emotions that I need to display toward others. (.89)

I work hard to feel the emotions that I need to show to customers. (.80)

I work at developing the feelings inside of me that I need to show to customers (.90)

Variety of Emotions (developed from Brotheridge and Lee, 2003)

Display many different kinds of emotions (.87)

Express many different emotions (.94)

Display many different emotions when interacting with team mates .92

Emotional Dissonance (developed from Cheung and Tang, 2012)

In order to satisfy team requirements and expectations I would deliberately express certain emotions which I don't necessary feel. (.90)

During my work hours, my external emotional expression is different from my genuine feeling. (.98)

My emotional expression is entirely based on team requirements and expectations, it is not my genuine feeling.

Sometimes, the team required emotional expression differs from my genuine feeling. (.94)

When dealing with team mates, my expressed emotions differ from my genuine feelings. * 